\title{
Charlie Hebdo: Consciência histórica sobre intolerância religiosa de estudantes de Goiânia
}

\author{
Charlie Hebdo: Historical Consciousness on Religious Intolerance of \\ Goiânia Students
}

\author{
Maria da Conceição Silva ${ }^{1}$ \\ Enelice Milhomem Jacobina Teixeira ${ }^{2}$
}

RESUMO

A presente pesquisa analisa o sentido da intolerância religiosa a partir de estudos sobre o atentado ao Semanário Charlie Hebdo, ocorrido em janeiro de 2015, na cidade de Paris. As fontes investigadas foram as narrativas de estudantes de uma Escola da Secretaria Municipal de Educação em Goiânia, coletadas entre 2015 e 2017, por meio de instrumental de investigação, que teve como objetivo indagar a postura, contrária e favorável, dos estudantes aos terroristas ou aos cartunistas. O aporte teórico desenvolvido pela educação histórica possibilitou fazer intervenções para o aprofundamento de estudos sobre intolerância. Após as intervenções, aplicamos o instrumental de investigação pela segunda vez, a fim de verificarmos se houve alterações nas aprendizagens. Identificamos pouco avanço em relação à postura dos estudantes sobre a liberdade de expressão de religiosos e não religiosos. Fizemos uma terceira intervenção, com questões relacionadas ao motivo das charges serem ofensivas à religião Islâmica e a explicação sobre o que é intolerância religiosa na atualidade. Percebemos nessas narrativas a existência de alterações; alguns estudantes demonstraram mudança na consciência histórica para uma orientação crítica e genética.

Palavras-chave: Semanário Charlie Hebdo. Intolerância Religiosa. Consciência Histórica. Educação Histórica. História.

ABSTRACT

The present research analyzes the significance of religious intolerance from studies on the attack on Charlie Hebdo Weekly in January 2015 in the city of Paris. The sources investigated were the narratives of students of a School of the Municipal Secretary of Education of "Goiânia", collected between 2015 and 2017, through research instruments, whose objective was to investigate the contrary and favorable position of the students to the terrorists or to cartoonists. The theoretical contribution of historical education made it possible to carry out interventions for the study of intolerance. After the interventions, we applied the research instrument a second time to check for changes in learning. We have identified little progress in relation to students' positions on religious and non-religious freedom of expression. We made a

1 Professora na Faculdade de História e no Programa de Pós Graduação em História da Universidade Federal de Goiás. Email: mariacsgo@gmail.com

2 Mestre em História pela Universidade Federal de Goiás. Professora de História da Rede Municipal de Educação em Goiânia. E-mail: enelicem@gmail.com 
third intervention, with questions related to the motive of the cartoons being offensive to the Islamic religion and the explanation of what is religious intolerance today. We perceive in these narratives the existence of alterations; some students demonstrated a shift in historical consciousness to a critical and genetic orientation.

Keywords: Weekly Charlie Hebdo. Religious intolerance. Historical Consciousness. Historical Education. Story.

\section{Introdução}

A pesquisa traz análises de problemáticas constitutivas de demandas da sociedade contemporânea, em geral, e no Brasil em particular, cujo objetivo é investigar carências de orientação temporal e espacial de estudantes da educação básica acerca do tema intolerância religiosa. Nesse sentido, o nosso foco versa em estudos de temas sociais controversos, constituintes do universo cultural de adolescentes e jovens em ambiente escolar. A problemática da intolerância religiosa é objeto de estudos sobre elementos culturais e religiosos do imaginário dos estudantes, muitas vezes, não compartilhados e, muito menos, inseridos em aulas de História como: Temas sociais controversos e aprendizagem histórica, desafios contemporâneos.

Os estudos sobre intolerância religiosa trazem resultados que nos posiciona diante de reflexões para o sentido de se ensinar História a esses jovens adolescentes, nesse tempo presente da História do Brasil. Por esse viés, observamos que as pesquisas no campo da educação histórica têm indicado resultados que permitem identificar dificuldades escolares relacionadas a temas delicados, sensíveis ou controversos da história europeia recente e do Brasil. Temas que sugerem um olhar atento sobre investigações que problematizem e indiquem caminhos para a construção de uma escola mais justa, em que o tipo e a forma das relações não influenciem, também, a multiplicação das desigualdades sociais e culturais. Desse modo, a problemática da investigação ocorre a partir de estudos sobre o atentado ao Semanário Charlie Hebdo ${ }^{3}$, ocorrido no dia 7 de janeiro de 2015, na cidade de Paris. Diante do exposto, cabe explicar que produzimos, nesta pesquisa, muito mais que um exercício de reflexão histórica sobre a intolerância religiosa. Cabe também elencar a relevância de referência no campo da educação histórica para a coleta e análise das fontes

3 Segundo Liliane de Lucena (2015, p. 5): O jornal Charlie Hebdo: Em 1969, é publicada pela primeira vez a Hara-Kiri Hebdo, com a mesma proposta de falar de tabus e criticar política, religião, entre outros temas espinhosos [...] E no ano de 2011 , a redação foi atacada e destruída por uma bomba incendiária. Os ataques de 7 de janeiro de 2015 foram arquitetados para matar o maior número de profissionais do jornal, uma vez que foi escolhida a hora emblemática de reunião de pauta. No total, foram 17 vítimas, além de três terroristas mortos pela polícia francesa. 'Vingamos o profeta!', era a frase dita pelos atiradores após o massacre na redação. 
principais. Estas se constituíram nas ideias prévias dos estudantes; jovens entre 12 e 16 anos de idade, do CICLO III ${ }^{4}$, das turmas "Gs" (7ํ. ano) e turmas "Is"(9‥ ano), do ensino fundamental, da Escola Municipal Ana das Neves de Freitas, localizada na cidade de Goiânia. Durante a investigação, os estudantes avançaram nas etapas do CICLO III, uma vez que a investigação durou três anos. Iniciamos em setembro de 2015 e finalizamos em setembro de 2017. A coleta das narrativas dos estudantes ocorreu por meio de instrumentais de investigação (Anexo A e B), nas quais observamos aspectos importantes sobre a história recente que foram narrados por eles. São escritos que refletem tipos de consciência histórica sobre intolerância religiosa no ambiente escolar, sem, contudo, desconsiderar o ambiente fora da escola.

\section{A Importância da Educação Histórica a partir das Tipologias de “Consciência Histórica”, de Jörn Rüsen}

A escola como local de ensino-aprendizagem carece oportunizar aos estudantes o contato com a metodologia de ensino e as pesquisas desenvolvidas, atualmente, no campo da educação histórica. Esse campo que é parte do ensino da história tem desenvolvido perspectivas instigantes a partir das tipologias de consciência histórica de Jörn Rüsen e de outros teóricos, entre os quais podemos mencionar os estudos de Peter Lee, na Inglaterra; Isabel Barca, em Portugal, e estudos pioneiros de Maria Auxiliadora Schmidt, no Brasil; entre outros. Com isso, têm-se possibilitado relevantes análises a partir de fontes, narrativas de estudantes, com temas diversos social e culturalmente.

Apreendemos com Jörn Rüsen, quatro tipologias de orientação temporal. O autor as explica como sendo "[...] formas de uma tipologia geral do pensamento histórico" (SCHMIDT; BARCA; MARTINS, 2010, p. 61). A consciência histórica realiza sua função através das tipologias, que permitem aos estudantes a orientação temporal, cultural e a interpretação das práticas de vida. Rüsen as categoriza em:

\footnotetext{
a) O tipo tradicional: As tradições são elementos indispensáveis de orientação dentro da vida prática, e sua negação total conduz a um sentimento de desorientação massiva. A consciência histórica funciona em parte para manter vivas essas tradições.

b) O tipo exemplar. Aqui a consciência histórica se refere à experiência do passado na forma de casos que representam e personificam regras gerais de mudança temporal e a conduta humana.
}

\footnotetext{
4 A Proposta Política Pedagógica para a Educação Fundamental da Infância e da Adolescência da Prefeitura Municipal de Educação de Goiânia: Os Ciclos de Formação e Desenvolvimento Humano, em Goiânia, preveem a organização dos educandos da seguinte forma: Ciclo I - Ciclo da Infância (6 a 8 anos), Ciclo II - Ciclo da Pré-adolescência (9 a 11 anos) e o Ciclo III - Ciclo da Adolescência (12 a 14 anos) (GOIÂNIA, 2012, p. 177-196).
} 
c) O tipo crítico: O pensamento histórico-crítico aclara o caminho para a constituição da identidade pela força da negação.

Sua contribuição aos valores morais se encontra em sua crítica dos valores. Desafia à moral apresentando o seu contrário.

d) O tipo genético: Aqui a mudança é a essência e o que dá à história seu sentido. $O$ futuro supera, excede efetivamente o passado em seu direito sobre o presente, um presente conceituado como uma intersecção, um nó intensamente temporal, uma transição dinâmica.

A ideia dos Direitos Humanos Universais é outro exemplo que demonstra a plausibilidade desta forma genética de argumentação em relação aos valores morais (SCHMIDT; BARCA; MARTINS, 2010, p. 62-71).

A reflexão dessas tipologias de consciência histórica nos conduzem à reflexões das pesquisas em espaço escolar, lugar de ensino-aprendizagem e também de convício social. É, portanto, um ambiente de desenvolvimento de pensamento e também da emergência de ideias controversas. Cada estudante ao adentrar à escola traz consigo uma história de vida, que é marcada por histórias diversas. Esse estudante precisa compreender contextos históricos não apenas como acontecimentos de causas e consequências, mas como o tempo histórico é acontecimento real num determinado espaço social.

Diante do exposto, consideramos que os estudos de Rüsen têm propiciado contribuições precisas sobre a importância da didática da história, sobretudo, para o campo que vai se fortalecendo e denomina-se educação histórica. Este campo vem construindo metodologias para o ensino e a pesquisa em história, nos propiciando observar as carências de aprendizagem dos estudantes e também dos procedimentos adequados para o ensino de contextos sociais diversos. Hoje, porém, no campo da educação histórica já se debate os usos e as funções da história na vida pública para além do espaço da escola. Não obstante, precisamos avançar cientificamente nas pesquisas sobre os usos públicos da história, seja a escolar e de outros lugares sociais. Assim, os estudos sobre intolerância religiosa a partir do acontecimento ao Semanário Charlie Hebdo em Paris, como instrumento de investigação, objetivou constituir princípios de compreensão do mundo para além do ambiente escolar, uma vez que a atualidade requer dos estudantes e de pessoas comuns uma prática transformadora da sociedade.

A mídia noticiou o atentado do dia 7 de janeiro de 2015, em Paris, notadamente, na França e o reportando como ato de intolerância das duas partes envolvidas, terroristas e cartunistas do Hebdo. Apreendemos as notícias sobre esse atentado terrorista para o ensino-aprendizagem histórica e a coleta das narrativas dos estudantes; mas o nosso objetivo principal de ensino e pesquisa estava posto como questões relacionadas à intolerância religiosa. Analisamos em aulas de história, de forma simplificada, os grupos radicais do Islamismo na França, bem como seu espaço territorial, religioso e cultural e o aumento da população de tradição islâmica no território francês. O ataque ao Semanário 
Charlie Hebdo culminou na morte de doze pessoas, cartunistas. Daí abordamos assuntos da violência como resultados de conflitos entre a liberdade de expressão dos cartunistas e à fé islâmica.

Os estudos realizados com os estudantes sobre o atentando no dia 7 de janeiro em Paris, nos possibilitou acessar as ideias prévias do grupo participante, nas quais observamos mais atentamente questões ligadas ao cotidiano desses estudantes. Nesse sentido, o trabalho didático sobre o acontecimento no Semanário Charlie Hebdo foi o fio condutor à problemática - intolerância religiosa - que nos possibilitou perceber concepções de intolerância entre os envolvidos, cartunistas e terroristas. Daí, podemos dizer que reivindicar a liberdade de expressão num mundo dominado pelas verdades absolutas é muito complexo, sobretudo, quando se objetiva afrontar o indivíduo; quando a crença é marcada por anos como verdade absoluta e inquestionável, como assim é a posição de fieis da cultura Islâmica.

\section{Narrativas sobre Intolerância Religiosa a Partir de Estudos do Semanário Charlie Hebdo}

Além da coleta das narrativas dos estudantes realizamos aulas-oficinas, seguindo o modelo metodológico sugerido por Barca (2004). As tarefas realizadas em distintas etapas serviram de fontes para investigarmos conhecimentos prévios dos estudantes sobre o que é a religião islâmica e o atentado ao Semanário Charlie Hebdo, ocorrido em janeiro de 2015.

No primeiro estágio da coleta, as reflexões dos estudantes demonstraram uma consciência histórica do tipo tradicional, tendo como referencial as ideias iniciais sobre religião e violência, limitadas ao senso comum de suas vivências. Assim, podemos afirmar com toda convicção acerca das ideias colocadas por Rüsen, de que existe a uniformidade dos grupos tradicionais da sociedade. Mantêm-se, assim, a coesão entre as pessoas quando alimentam a tradição, dificultando a percepção das diversas interpretações da história: "Essas orientações tradicionais definem a 'unidade' dos grupos sociais ou das sociedades em seu conjunto, entretanto mantêm o sentimento de uma origem comum" (SCHMIDT; BARCA; MARTINS, 2010, p. 64).

Os conflitos entre os cartunistas e os islâmicos extremistas como vistos pelos estudantes, aparentemente, seriam uma questão fácil de ser resolvida; todavia, apresentaram dificuldades em ver o atentado como um ato baseado em conflitos complexos, de cunho cultural e religioso. As primeiras narrativas foram coletadas sem que os estudantes tivessem contato com qualquer material sobre o atentado ao Semanário Charlie 
Hebdo. Apresentamos algumas delas e percebemos como os estudantes ficaram divididos, uma vez que demonstraram um tipo de conhecimento histórico influenciado pelos aspectos religiosos, familiares e pela mídia. Destacamos algumas respostas sobre a percepção do que seria a religião islâmica, a exemplo da narrativa da Mary, estudante da turma G2: "Que ela é uma religião muito rígida, que tem muitas histórias e atentados terroristas". A resposta da estudante evidencia um juízo de valor ao afirmar que os islâmicos são rígidos e não gostam de outras religiões. A estudante compreende ser o Islamismo uma religião, conceito importante, considerando que muitos apresentaram dificuldades para aceitar outra corrente religiosa diversa à que professa, mesmo sendo capazes de reconhecerem o Islamismo como religião a partir de conteúdos didáticos estudados no sétimo ano do ensino fundamental.

O campo da educação histórica propiciou condições para que os estudantes participassem das oficinas sobre a intolerância religiosa. Dessa forma, puderam observar a importância do debate a respeito da interculturalidade, de como a história é instrumento de orientação no sentido de formar opiniões sobre os diversos assuntos entre os temas controversos e sensíveis socialmente. E, assim, desenvolverem condições intelectuais para orientação e decisões futuras. A partir das divergências entre as religiões, os estudantes construíram as narrativas, como se observa:

\footnotetext{
Eu aprendi varias coisas, e o principal, o mais interessante que eu achei foi que os mulçumanos tem batalhas com os Judeus, para disputar algumas coisas, isso foi uma das coisas que eu mais achei interessante (Eva, G1).

A religião islâmica é uma religião diferente da nossa por conta das suas vestes dos seus preceitos e de suas vidas secundárias que são muito diversificadas. A religião islâmica ela é forte e contém muitas guerras e muitos terrorismo por conta do embate com outros países que não são de acordo com seus preceitos e suas decisões eleitorais, etc... (Carla, I 2).
}

A estudante Eva consegue ver o conflito existente entre mulçumanos e judeus, abordando divergências entre duas religiões diferentes. Carla extrapola o senso comum, percebe que a religião islâmica é diferente da qual ela frequenta. A estudante ressalta as diferenças culturais, por exemplo, nas vestes, que são diferentes; e que as guerras em que se envolvem são motivadas também pela não aceitação, por outros povos, das escolhas dos mulçumanos por preceitos cristãos, que extrapolam o âmbito político das leis.

Usamos critérios de separação da participação dos estudantes ${ }^{5}$, da seguinte forma: os que disseram ser favoráveis a atitude dos terroristas, os que se identificaram com a atitude dos cartunistas, e os que acharam imprudentes as duas opções e procuraram uma resposta para além. A maioria dos estudantes optou por ser terroristas, se estivesse no atentado ao

5 Sessenta e um estudantes participaram. 
Semanário Charlie Hebdo, no dia 7 de janeiro de 2015. Uma pequena porcentagem dos estudantes optou pelos cartunistas e uma quantidade menor optou por neutralidade. Vejamos exemplos dos que optaram pelo terrorismo:

\begin{abstract}
Eu não seria nenhum dos dois, mais se fosse algum deles eu seria o terrorista só pra ser temido mais eu não ia fazer nada de ruim a ninguém (Hugo, I2).

Um terrorista eu ia matar os cartunista porque eles estavam com racismo contra os islâmicos eles estavam fazendo besteiras com eles tipo um racismo prejudicando a religião, eu acho uma falta de respeito (Cristina, G2).
\end{abstract}

Os estudantes que optaram pela posição dos terroristas demonstraram ser compreensível à violência em defesa da religião, mesmo não sendo a religião deles. As narrativas desses estudantes estão carregadas de violência e, muitas vezes, a fé foi e é a justificativa para a violência contra pessoas que discordam das suas verdades, ou que fazem calúnias e sarcasmos em relação aos seus deuses. Observamos que a intolerância religiosa, o preconceito e a não aceitação das posturas e à expressão de pensamentos de pessoas contrárias justificaram as mortes para diversos estudantes. Essas narrativas seriam do tipo tradicional (Rüsen), mas quando o indivíduo não segue determinado comportamento de tradição do seu grupo de convivência, "ocorre um sentimento de desorientação massiva." (SCHMIDT; BARCA; MARTINS, 2010, p. 62). Mas, também, notamos em algumas narrativas a emergência de consciência histórica exemplar. A ação no presente é fundamentada em exemplos passados. A violência narrada por esses estudantes, por serem terroristas, na hipótese de terem participado do atentado ao Semanário Charlie Hebdo, denunciou as suas concepções religiosas.

As narrativas sobre a intolerância religiosa dos estudantes favoráveis aos cartunistas mostraram um perfil de concordância com a liberdade de expressão por defenderem o direito do outro de ser contrário às ideias, que desafiam a sociedade com sátiras. Narrativas dos favoráveis aos cartunistas:

\footnotetext{
Meu sentimento seria tristeza, por muitas pessoas morrendo, um lugar destruído. Eu seria um cartunista, porque o terrorista está matando pessoas mas o cartunista não, ele publicou uma matéria e os mulçumanos se sentiram ofendido e praticaram a violência, então cartunista (Ana, G1).

O cartunista. Porque poderia relatar e expressar do jeito que eu entendesse, para mostrar as pessoas o mundo em que vivemos e pessoas que estão em volta. E para demonstrar a minha opinião de algo que eu possa concordar de não através de charges ou frases que dizem a respeito de situações diversas. Entre elas o ataque na sede do Jornal de Charlie Hebdo em Paris (Carla, I2).
}

Com argumentos diferentes, as estudantes apresentaram ideias favoráveis aos cartunistas, sobretudo, por não serem favoráveis ao assassinato, ao terror, à vingança; 
outros já se posicionaram, dizendo que o Semanário fazia a crítica e, portanto, se equivocava, pois não se comparava ao peso de se tirar uma vida, matar uma pessoa.

Alguns estudantes escolheram ser cartunistas por acreditarem que a charge é um instrumento de protesto pacífico, sem armas e sem violência. Mas, no mundo simbólico religioso é complexo e, ao mesmo tempo, confuso distinguir o que é pacífico ou violento. Para seguidores do Islamismo, caluniar, denegrir, satirizar suas crenças e seus rituais é um insulto, que se constituem é uma agressão e desmoralização, uma vez que representam uma forma de violência sem limites. Poucos estudantes optaram pela imparcialidade. Talvez a maioria insistiu em se posicionar para um dos lados, com a percepção de que existem dois lados distintos e bem delimitados; um que representa o bem e a justiça e o outro representa o mal e a injustiça. Todavia, o referencial sobre o que seria "bom" ou "justo" foi diferente para os que optaram por ser terroristas ou cartunistas. Os estudantes que não optaram por nenhum dos lados, se recusaram a apoiar tanto as agressões midiáticas quanto a violência terrorista de grupos radicais islâmicos. Assim, as estudantes expressaram que:

\footnotetext{
Eu não seria o terrorista mais também não acho certo falar de uma religião dessa maneira mesmo sendo uma protesto porque ofende a religião deles e por tanto não seria o cartunista também não seria nem um dos dois (Thais, G1).

Eu iria ficar assustada e com medo, porque apesar das coisas que os outros tinham feito, isso não e uma coisa normal, nem elegante de se ver então tenho quase certeza de que eu não seria a terrorista, pra mim isso é uma situação bem crítica (Eva, G1).
}

Não é a religião que nos induz a respeitar, identificar, interagir com o outro, mas a solidariedade que se expressa entre as pessoas, consideramos que seja interculturalidade. Todavia o que presenciamos, nesse momento, é uma sociedade que traz nuances de desagregação e nega o avanço da interculturalidade. Eva não se alia a nenhuma das possibilidades por não admitir o preconceito, mortes, opressões, independentemente da religião, bem como a questão étnica e de nacionalidade. Percebemos a neutralidade declarada pela estudante ao apresentar uma consciência crítica perante a proposta dualista, de ser cartunista ou terrorista. A estudante não admite, se diz neutra, afirmando que a vida deve ser preservada, independente das diferenças entre as pessoas.

\section{A Intolerância Religiosa e o Atentado ao Semanário Charlie Hebdo: a Percepção dos Estudantes}

O conhecimento dos estudantes sobre a religião islâmica e aos atentados terroristas nos pareceu ser superficialmente de senso comum. Diante dos resultados de opção pela ação dos terroristas, realizamos oficinas de intervenção com textos didáticos e textos de pensadores como Boaventura Souza Santos, Demant, Melo, entre outros que estudam 
religião e religiosidade. O nosso objetivo foi possibilitar o desenvolvimento da consciência histórica mais crítica no tocante à investigação sobre intolerância religiosa no mundo atual. Assim, as oficinas além de propiciar o desenvolvimento da consciência histórica dos estudantes objetivavam fazer reflexões sobre o conflito entre os franceses, notadamente no que se refere ao atentado, bem como a intolerância religiosa em outros países da Europa e também no Brasil. Propusemos essa experiência a partir de estudos por meio de esquemas na lousa, acrescentamos, ainda, elementos sobre a colonização europeia na África e Ásia, ressaltando a exploração europeia sobre países nos continentes africano e asiático.

Realizamos oficinas a partir de estudos em textos didáticos (CARDOSO, 2012) sobre temas como: Protestantismo e a Reforma Católica (1517-1563), Corrupção na Igreja (15171563), Conflitos e a Reforma Católica, Formação de Portugal e da Espanha (1139-1492), entre outros. Os textos foram lidos e debatidos no sentido de despertar reflexões sobre o atentado ao Semanário Charlie Hebdo e dos atentados terroristas na Europa desde 2004. Propiciamos, ainda, que os estudantes participassem das oficinas em aulas e pesquisassem em casa e em ambiente das TICs na própria escola. Aplicamos o instrumental de investigação, pela segunda vez, em agosto de 2017. Após a investigação fizemos análises das narrativas, realizamos ainda uma avaliação sobre o atentado ao Semanário Charlie Hebdo, com a intenção de percebermos se havia a ocorrência de mudanças relacionadas à consciência histórica dos estudantes. Em agosto de 2017, quando aplicamos o instrumental de investigação, num segundo momento, consideramos que os estudantes já tinham participado das oficinas. Primeiramente apresentamos, as narrativas deles sobre o que é religião islâmica, e, em seguida, projetamos uma amostragem do percentual de favoráveis aos terroristas ou dos cartunistas e dos que se posicionaram neutros. Aqui apresentamos narrativas de três estudantes, do segundo momento de aplicação do instrumental (2017), sobre o que é a religião islâmica:

Que eles são muito fechados e não aceitam opiniões e outros tipos de orientações de coisas que não são da suas religiões (Carla, I2).

Em religião islâmica com vários grupos e alguns bem radicais, que são os terroristas (Mary, 12).

Aprendi que a religião islâmica é uma religião muito rígida, que qualquer deslize pode custar a vida, e que seus seguidores são a maioria radicais (Carlos, I2).

A estudante Carla ao participar das intervenções apresentou uma postura de consciência crítica. Ela mencionou a falta de abertura dos seguidores do islamismo com outras práticas religiosas; para eles não existem outras religiões. Mary apresentou posturas críticas quando destacou que a religião islâmica tem vertentes, algumas com perfil terrorista, destacando, assim, o reconhecimento de diferentes correntes no interior da religião, afirmou 
que nem todos são radicais. O olhar desses estudantes é de uma consciência com perfil relativizadora, demonstrando que os estudos em oficinas de intervenção propiciaram alguma diferença em suas reflexões sobre religião num mundo intercultural. Em uma segunda análise da aplicação do instrumental de investigação, sobre intolerância religiosa, os que se mostravam favoráveis aos cartunistas, apresentaram uma visão unilateral. Os cartunistas defendem posturas de produtores de ideias e de reflexões sobre o fanatismo de fieis seguidores - do Islamismo. Assim, esses estudantes deixaram de se colocar no lugar dos islâmicos, provocando uma atitude de compreensão de um lado. Thiago Ramos de Melo (2016, p. 128-129) ao estudar charges chama a atenção, dizendo que:

\begin{abstract}
Embora as charges dessa temática aparentem uma preocupação em separar a figura do mulçumano da figura do terrorista, a crítica feita por elas é unilateral, voltada para o ataque ao fundamentalismo islâmico, ao passo que silenciam diante da postura ridicularizadora que o jornal Charlie Hebdo tinha com a religião islâmica, dissimulando o conflito de posicionamentos existente sobre o tema. Desta forma, as charges posicionam-se ideologicamente em defesa do semanário, omitindo-se e omitindo o outro lado da discussão.
\end{abstract}

Para Melo, as charges expõem uma ideologia que desconstrói o islamismo ao invés de discuti-lo com coerência. Os estudantes ao terem a oportunidade de debatê-las destacaram a importância da liberdade de expressão tão valorizada pelos franceses; a exemplo da estudante Carla que diz:

Cartunista. Eu acho que cada um tem direito de expressar suas opiniões e suas ideias e cada um tem que ter livre arbítrio e ter sua própria decisão nas atitudes que devem ser tomadas na sociedade. A vida é feita de escolhas e cada um tem direito de escolhe-las. O ser humano tem que se impor e fazer o que acha que é certo (Carla, I2).

Cartunista, eu faria vários desenhos de como tudo começou (Eliane, I2).

A estudante reforçou o pensamento que produziria charges independentemente dos resultados, posicionando-se, portanto, pela continuidade da produção de charges. Ela propõe produzir charges para historicizar a trajetória do Semanário Charlie Hebdo desde o seu início; posicionamento que pode emergir em diálogos religiosos e sociais para a compreensão do que é interculturalidade.

Outra identificação dos estudantes demonstra que a morte passou a ser natural cotidianamente. Quando a morte é banalizada, ela pode simbolizar a única via possível entre os indivíduos. As narrativas dos estudantes Luiz e Mary descrevem a opção pelo terrorismo: 
Queria ser o terrorista, porque eu queria explodir as pessoas e poder matar as pessoas (Luiz, I1).

Eu seria o terrorista, e mataria todo mundo mesmo pois achei uma falta de respeito, pois não podemos fazer esse tipo de coisa com religiões, se eu fosse um islâmico eu me sentiria muito ofendido (Mary, I2).

Em algumas narrativas, a violência antecede qualquer possibilidade de diálogo, o que consideramos muito grave para a construção da interculturalidade e da democracia. A estudante Katia destacou que mataria em represália ao racismo e preconceito. Assim, ela alega que a questão justifica o terrorismo, destacando que o racismo prejudica a religião:

\footnotetext{
Um terrorista eu ia matar os cartonistas porque eles estavam com racisco (racismo?) contra os islâmicos eles estavam fazendo besteiras com eles, tipo um racismo prejudicando a religião, eu acho uma falta de respeito (Katia, I2).
}

A identidade de exclusão social, provavelmente, induz os estudantes a afirmarem ser favoráveis aos terroristas, ou pelos cartunistas terem difamado, agredido, insultado e desrespeitado tantas religiões. Os estudantes incluem as suas crenças, como se os terroristas tivessem feito as charges contra eles em particular. Vejamos a postura desse estudante:

\footnotetext{
Ficava do lado dos terroristas porque não havia necessidade dos cartunistas fazer estas coisas pesadas com a religião e acho que os cartunistas teriam que respeitar mais todas as religiões (Carlos, I2).
}

A opção por ser terroristas evidencia a concordância aos terroristas, defendendo preceitos de violência. Na segunda aplicação do instrumental, somente a estudante Eva se posicionou pela neutralidade. Ela defendeu a necessidade de sermos tolerantes com o pensamento religioso do outro. Eva, por sua vez, declarou: "Nenhum dos dois. Ninguém merece morrer, e ninguém merece ser oprimido e ser alvo de preconceito" (Eva, I1).

Não é a religião que traz o respeito, o identificar-se e, ao mesmo tempo, o interagir com o outro; a solidariedade produz a interculturalidade, o respeito no processo de cidadania. O que presenciamos, nesse momento, é uma sociedade segregada que dificulta a interculturalidade. Eva não se agrupa a nenhuma das possibilidades, notadamente, por não admitir o preconceito, às mortes e opressões, independentemente da religião, da etnia e da nacionalidade. A neutralidade declarada da estudante é de uma consciência crítica, diante da proposta dualista de ser cartunista ou terrorista. Ela se diz neutra, defende que a vida deve ser preservada, independentemente das diferenças entre as pessoas.

Os dois momentos da investigação com as diferenças percentuais nos resultados do instrumental de investigação podem ser observados no gráfico 1. Os resultados foram quantificados a partir das posições coletadas em 2015 e 2017. O nosso objetivo foi de 
realizarmos um quadro comparativo com análises acerca das alterações da consciência histórica dos estudantes. Assim, apresentamos uma análise comparativa entre os gráficos 1 e 2.

As narrativas dos estudantes, segunda aplicação do instrumental, acerca de intolerância religiosa, observamos que os favoráveis aos terroristas aumentaram (Gráfico 2). Inicialmente, pensávamos que após as oficinas de intervenção ocorreria, no mínimo, a escolha pela neutralidade ao atentado, que houvessem explicações fundamentadas de compreensão intercultural. Mas, o que vimos foi o aumento no percentual de favoráveis ao atentado. A explicação para essa postura, a partir das análises realizadas durante a investigação, pode estar relacionada à identificação dos estudantes com a religião, de modo geral. Portanto, as narrativas sobre o que é a religião islâmica, no segundo momento da investigação, mostraram-se superficiais e limitadas ao senso comum. O conhecimento sobre religião abrangia à concepção cristã católica e evangélica. E sobre a intolerância religiosa percebemos que as intervenções não produziram alteração de consciência histórica, o que houve foi um tipo de similaridade entre as primeiras narrativas do instrumental de investigação em setembro de 2015 e, as últimas, de 2017.

Gráfico 1 - Participação no atentado do Semanário Charlie Hebdo - 7 de janeiro de 2015. Categorias: terroristas, cartunistas, neutros, não participantes. Data da aplicação: 22 setembro de 2015.

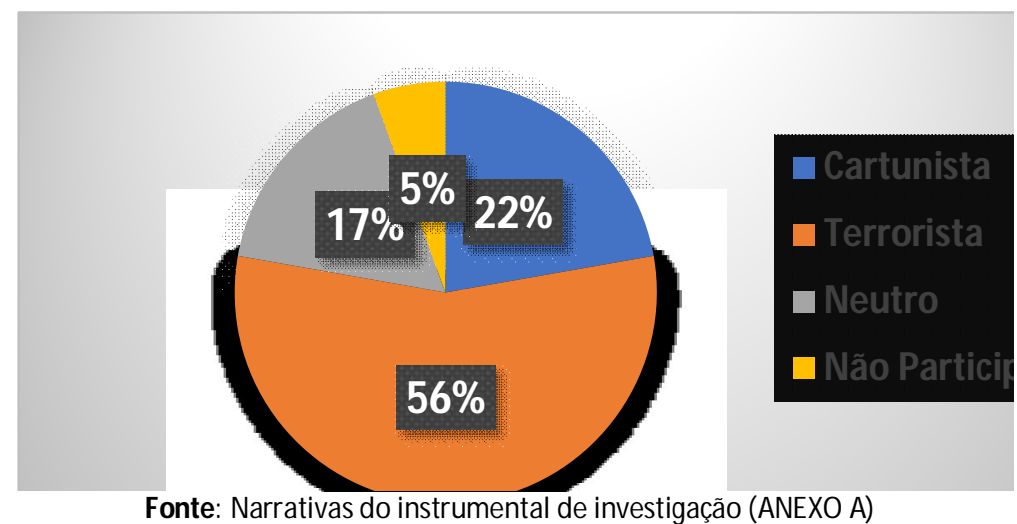

Fonte: Narrativas do instrumental de investigação (ANEXO A) 
Gráfico 2 - Participação no atentado do Semanário Charlie Hebdo, 7 de janeiro de 2015. Categorias:terroristas, cartunistas, neutro, não participantes. Realização: 22 de agosto de 2017.

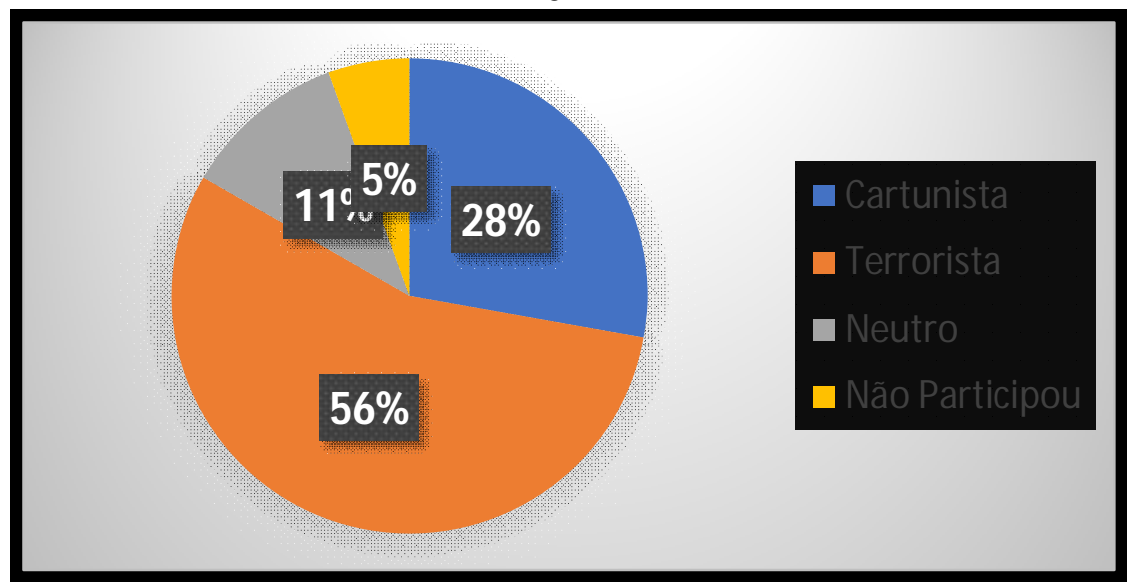

Fonte: Narrativas do instrumental de investigação (ANEXO A).

Assim, os resultados, no segundo momento de aplicação do instrumental, justificaram o repensar à pergunta e realizamos outra indagação através de uma avaliação trimestral, (Anexo B). A pergunta "a", motivo de as charges serem ofensivas a Religião Islâmica? Por um lado, a questão aprofunda à discussão da intolerância e, por outro lado, desperta, nos estudantes, a necessidade de reflexão, não somente sobre ser terrorista ou cartunista, mas no sentido de se posicionarem diante do inaceitável, independente do lugar de referência social.

Os estudantes perceberam, de forma crítica, a gravidade e o desenrolar de atitudes xenofóbicas, anti-imigrantes, etnocêntricas, desencadeadoras de conflitos em dimensão extensa mundialmente.

A estudante, Eva não questionou a barbaridade do ato terrorista. Entretanto, ela destacou o desrespeito, a intolerância dos cartunistas em relação aos islâmicos, que professam uma religião diferente em seu território. Destacou, ainda, que os cartunistas ao estimularem a violência, desrespeitaram os religiosos, quando produziram uma charge que apresenta um cartunista beijando Maomé, sendo que no Islamismo é proibido a produção de imagens do profeta. Para a estudante:

Os cartunistas fizeram uma charge em que um homem da religião islâmica beijava outro homem. Eram ofensivas a religião, por colocarem coisas ao contrário dessa religião (Eva, I1).

Eva narra, de forma coerente, como as charges feriam os princípios dos direitos humanos, pela barbárie. Pois, assim, se ofende às crenças do outro e insufla a guerra aos 
imigrantes islâmicos. Carla e Mary, nas narrativas citadas abaixo destacam, como a Eva, o afrontamento dos chargistas aos seguidores do Islamismo, pois desenham e desdenham de Maomé, ferindo os princípios religiosos. Entretanto, as estudantes não abordaram as razões das charges do Semanário Charlie Hebdo ofenderem a religião islâmica, apenas afirmaram que ofendeu, as consequências e não as razões. O estudante Caio conseguiu introduzir os motivos das ofensas quando afirmou que as charges sobre o islamismo atacam a vida, notadamente, a dos seguidores do Islamismo. Dessa maneira, esse estudante apresentou mudanças na consciência histórica, ampliando o seu conhecimento. Vejamos as narrativas:

\footnotetext{
Porque as charges 'tocam profundamente na vida' Do islamismo atacando seus ponto fraco (Caio, I1).

Porque é interpretada por mulçumanos como uma mensagem de que Alá não pode ser retratado em uma imagem feita por mãos humanas, sob sua beleza e grandeza. Daí uma crença islâmica que imagens levam à idolatria, no sentido de que uma imagem, e não o ser divino que ele representa, passa a ser objeto de adoração e veneração (Carla, I2).

Essas imagens estão "curtindo com a religião" tipo mostra esses mulçumano beijando o escritor e dentre outras coisas, é uma falta de respeito (Mary, I2).
}

A maioria dos estudantes, participantes da investigação, demonstrou repúdio a charges contra os islâmicos, sobretudo, à intolerância e às expressões religiosas de imigrantes na França. Consideraram ser inadmissível a produção de afrontamento ao outro. As produções dos estudantes vão de encontro ao que Thiago Ramos Melo ressalta quanto ao acirramento dos conflitos e de quando os chargistas optam por produzir charges antirreligiosas. Para Melo, esse tipo de atitude impossibilita a hegemonia em uma França multicultural, pois: "Ao omitir-se de discussões mais aprofundadas e que perpassam o tema, as charges legitimam indiretamente a desigualdade social e reforçam o preconceito que existe contra o mulçumano e a religião Islâmica, [...]" (MELO, 2016, p. 130). As charges instigam os conflitos e inviabilizam qualquer possibilidade de diálogo e de debate intercultural. Melo diz que os chargistas não foram capazes de dimensionar as consequências dos seus atos. Os estudantes não realizam esse tipo de análise. Os textos didáticos de história são estudados por esses estudantes; todavia, o que se observa é que eles não conseguem tecer maiores questionamentos sobre a história ensinada. Nesse sentido, é relevante apreendemos os caminhos do ensino e da pesquisa pela educação histórica, que possibilita analisar interpretações dos estudantes para além do senso comum, perspectivando a compreensão histórica, para a efetivação dos direitos humanos universais. Em educação histórica, o estudante não é um mero ouvinte, é interprete, investigador e, portanto, construtor do olhar crítico sobre o tempo histórico e seus desdobramentos, avançando em sua consciência histórica, para além das tradições e dos exemplos. 
A questão "b", trata-se de como a intolerância religiosa é vista em nossa sociedade. A questão foi assim formulada: - Explique o que é intolerância religiosa em nossa sociedade hoje? Os estudantes apresentaram os perigos da intolerância religiosa para a sociedade, a partir de conceitos importantes, como também perceberam a ausência de respeito às crenças do outro. As estudantes Eva, Eliane e Carla desenvolveram a ideia de que intolerância religiosa é o não respeito à diversidade religiosa, à imposição de religiões sobre professantes de outros grupos, a não aceitação da religião do outro.

\footnotetext{
Intolerância religiosa é quando uma pessoa não aceita a religião da outra, e luta contra a diversidade religiosa, achando que só uma é certa e que todos deveriam seguí-la (Eva, I1).

Não saber aceitar a religião de cada pessoa e afrontar as ideias ou cada religião que são estudadas e praticadas por pessoas religiosas (Carla, I2).

É você não suportar falarem daquela religião, você fica preso so a sua cultura e não conhece coisas novas, e fica odiando uma coisa que não conhece (Mary, I2).

É a discriminação contra as pessoas e grupos que têm diferentes crenças ou religiões, e é marcado principalmente pelas atitudes agressivas e ofensivas (Eliane, 12).
}

Os estudantes apresentaram as ameaças da intolerância religiosa para a humanidade, uma vez que se constroem divergências, impedindo, assim, a construção de uma identidade religiosa intercultural. A narrativa da Mary é indicativa da necessidade dos indivíduos aceitarem outros grupos religiosos e o respeito à especificidade cultural de cada grupo, com as suas doutrinas e crenças. Mary propõe desenvolvermos tolerância, notadamente, a interculturalidade. Quando adentramos ao mundo do outro, para compreender a sua religiosidade, devemos deixar de ser preconceituosos, para o desenvolvimento de relações de proximidade. A perspectiva da estudante aponta para o desenvolvimento da "consciência histórica genética". Ela destaca não somente a orientação temporal, mas a mudança e a transformação da sociedade presente e, consequentemente, futura, através da reorientação e reinterpretação dos estudos históricos acerca da religião. Nesse aspecto, as narrativas dos estudantes foram mais elaboradas, foi possível percebermos um tipo de consciência histórica mais avançada do que às narrativas apresentadas na aplicação do instrumental de investigação em 2015 e 2017. As perguntas elaboradas oportunizaram a possibilidade de maior reflexão e interpretação da intolerância religiosa, da religiosidade, da xenofobia, da segregação, entre outros importantes aspectos sociais e culturais relacionados aos sujeitos no presente. Percebemos, então, que esse tipo de instrumental de produção histórica nos possibilitou abordar o acontecimento de forma crítica e não dualista. 


\section{Considerações Finais}

Para reflexões sobre o acontecimento-chave desta pesquisa com outros parâmetros, sobretudo, o da violência, os estudantes examinaram mais imparcialmente o lado dos terroristas e dos cartunistas, percebendo e descrevendo conflitos de ambos os lados. Quando foram indagados sobre os motivos das charges do Semanário Charlie Hebdo serem ofensivas e sobre a intolerância religiosa na atualidade, eles observaram a existência de enfrentamentos das duas partes.

O objetivo inicial foi à discussão sobre intolerância religiosa, tendo como objeto o atentado ao Semanário Charlie Hebdo. Desse fio condutor, realizamos oficinas e análises, e propomos questões. Observamos avanços, retrocessos e apostamos em novas possibilidades de estudos, que alterassem a consciência histórica dos estudantes. Quando se inicia uma pesquisa, não se sabe os resultados que se chegam. Portanto, traçamos um percurso investigativo a partir de aulas e coletas. Assim observamos na medida em que os estudantes traziam as suas respostas e contribuições, repensávamos como continuar didaticamente a pesquisa, o que seria preciso acrescentar ou suprimir. Perguntávamos o tempo todo: -como poderíamos alcançar avanços no pensamento histórico dos estudantes durante à investigação? Consideramos, portanto, que é bem possível que os temas, bem como os conceitos chave, que, foram estudados e debatidos, possam interferir em outros desafios para o ensino-aprendizagem e pelos quais esses mesmos estudantes presenciarão em suas vidas futuramente.

\section{Referências}

BARCA, Isabel. Aula oficina: do projeto à avaliação. In: JORNADA DE EDUCAÇÃO HISTÓRICA, 4., 2004, Braga. Anais [...]. Braga: Universidade do Minho, 2004. p. 131-144.

CARDOSO, Oldimar. Leituras da história. 7º ano. São Paulo: Escala Educacional, 2012.

GOIÂNIA. Prefeitura Municipal de Goiânia. Secretaria Municipal de Educação. Proposta político-pedagógica para a educação fundamental da infância e da adolescência. Revista Inter-Ação, Goiânia, v. 37, n. 1, p. 177-208, jan./jun. 2012. Disponível em: https://www.revistas.ufg.br/interacao/article/view/18878/11248. Acesso em: 25 abr. 2017.

LUCENA, Liliane de. Os atentados ao Charlie Hebdo e seus desdobramentos. In: CONGRESSO BRASILEIRO DE CIÊNCIAS DA COMUNICAÇÃO, 38., 2015, Rio de Janeiro. Anais [...]. Rio de Janeiro: UFRJ, 2015. Disponível em: http://www.academia.edu/28629695/Os_Atentados_ao_Charlie_Hebdo_e_Seus_Desdobram entos_On_e_Off-Line. Acesso em: 14 out. 2017. 
MELO, Thiago Ramos. Enfrentamentos e tensões: uma análise de discursos de charges sobre o atentado ao Charlie Hebdo. 2016. Dissertação (Mestrado em Comunicação) Universidade Federal do Piauí, Teresina, 2016. Disponível em: http://repositorio.ufpi.br/xmlui/handle/123456789/342. Acesso em: 12 maio 2018.

PESCHANSKI, João Alexandre. Atentado contra a extrema-esquerda na França. In: BOITEMPO EDITORIAL. Blog da Boitempo. São Paulo, 7 jan. 2015. Disponível em: https://blogdaboitempo.com.br/2015/01/07/atentado-contra-a-extrema-esquerda-na-franca/. Acesso em: 2 set. 2016

REDAÇÃO PRAGMATISMO. As 6 charges mais polêmicas do Charlie Hebdo. In: PRAGMATISMO POLÍTICO. [S. I.], 7 jan. 2015. Disponível em: https://www.pragmatismopolitico.com.br/2015/01/charges-mais-polemicas-da-charliehebdo.html. Acesso em: 2 set. 2016.

REDAÇÃO PRAGMATISMO. Quem somos. In: PRAGMATISMO POLÍTICO. [S. I.], 22 jan. 2017. Disponível em: https://www.pragmatismopolitico.com.br/2017/01/quem-somos.html. Acesso em: 24 mar. 2018.

SCHMIDT, Maria Auxiliadora; BARCA, Isabel; MARTINS, Estevão de Rezende (org.). Jörn Rüsen e o ensino de História. Curitiba: Ed. UFPR, 2010. 


\section{Anexo A}

Instrumental de investigação das ideias prévias dos estudantes da Escola Municipal Ana das Neves de Freitas, Goiânia, a partir do atentado ao Semanário Charlie Hebdo intolerância religiosa e consciência histórica

\section{INSTRUMENTAL DE INVESTIGAÇÃO}

\section{I-IDENTIFICAÇÃO}

Aluno (a): Idade:

CICLO: III Turma:

Período: ( ) Manhã ( ) Tarde ( ) Noite

Qual é o grau de escolarização do seu pai?

Qual é o grau de escolarização da sua mãe?

Quantas pessoas moram em sua casa?

Que função você exerceu nesse trabalho?

Qual é a renda aproximada em sua casa?

Quais são os lugares que você frequenta em Goiânia?

Quais os lugares você gostaria de frequentar?

\section{II - PESQUISA CONCEITUAL TEMÁTICA}

\section{ATIVIDADE SOBRE O ATENTADO AO CHARLIE HEBDO}

\section{LEIA OS TEXTOS, OBSERVE AS CHARGES E RESPONDA AS PERGUNTAS:}

\section{1․ TEXTO}

ATENTADO AO CHARLIE HEBDO:

07/01/2015 09h21 - Atualizado em 08/01/2015 20h57

Ataque em sede do jornal Charlie Hebdo em Paris deixa mortos

Polícia francesa disse que 12 pessoas morreram e 11 ficaram feridas. Alvo foi sede de publicação satírica que já foi atacada por muçulmanos.

Do G1, em São Paulo

Pelo menos 12 pessoas morreram e 11 ficaram feridas em um tiroteio em Paris nesta quarta-feira (7). O crime aconteceu no escritório do jornal satírico "Charlie Hebdo", que já havia sido alvo de um ataque no passado após publicar uma caricatura do profeta Maomé...

Segundo fontes policiais, os autores do ataque portavam rifles Kalashnikov e gritaram "Vingamos o Profeta!", em referência a Maomé, alvo de uma charge publicada há alguns anos pelo jornal, o que provocou revolta no mundo muçulmano.

\section{TEXTO:}

O QUE É O SEMANÁRIO CHARLIE HEBDO?Por João Alexandre Peschanski, no Blog da Boitempo (PORTAL FORUM) 08.01.2015.

O Charlie Hebdo, cuja redação foi alvo de um atentado terrorista em 7 de janeiro de 2015, é um veículo de comunicação de extrema-esquerda. A origem política e artística dos principais nomes do veículo remonta aos anos 1960 na França. É a essa geração original que pertenciam Cabu e Wolinski, que estão entre as doze vítimas confirmadas até o momento em que escrevo este texto, com vários feridos ainda em estado grave. A marca inicial soixantehuitarde - dos participantes dos protestos de 1968 - está impregnada em toda a trajetória do semanário satírico.

Redação Pragmatismo Editor(a) TERRORISMO07/JAN/2015 ÀS 18:11

AS 6 CHARGES MAIS POLÊMICAS DO CHARLIE HEBDO 
Confira as charges e capas mais polêmicas do Charlie Hebdo, o jornal da França que costuma publicar conteúdo satírico sobre o islamismo e seus símbolos

Figura 1 - As 6 charges mais polêmicas do Charlie Hebdo

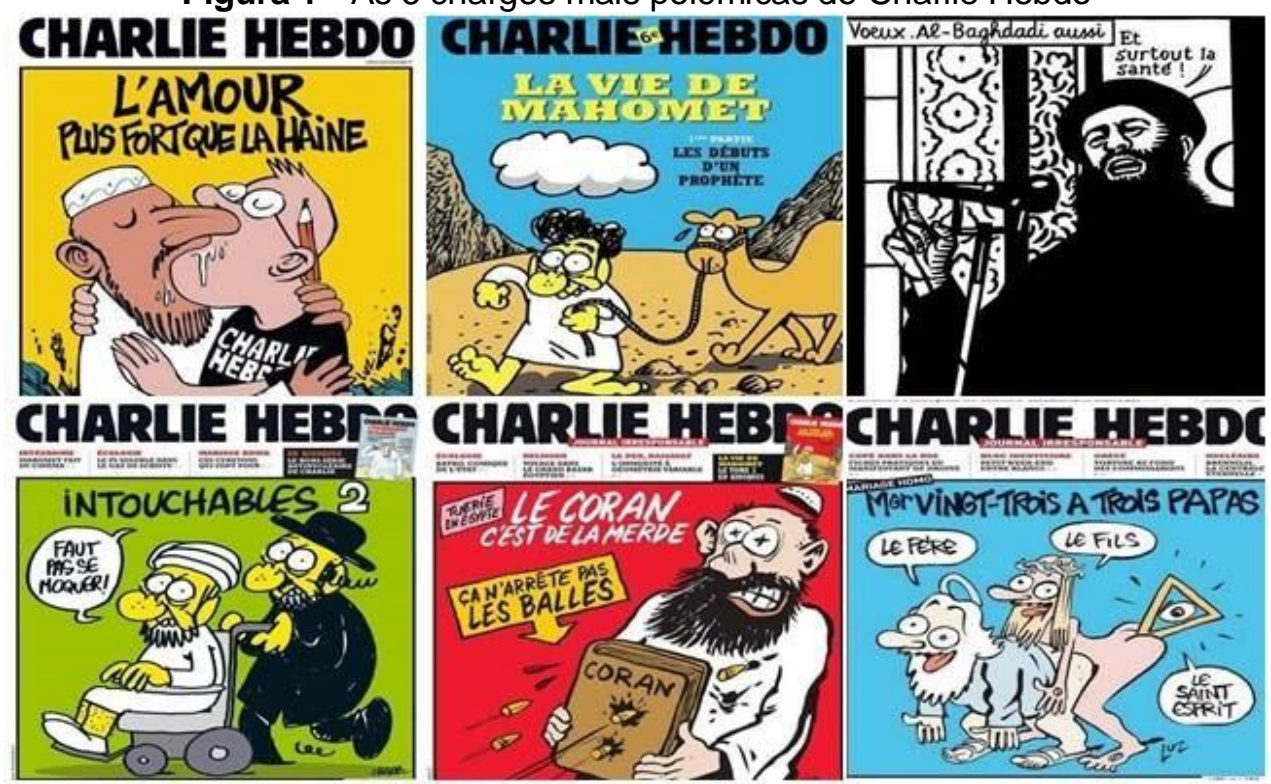

Fonte: Pragmatismo Político. ${ }^{6}$

RESPONDA COM SUAS PALAVRAS:

Imagine que você estava no dia 7 de janeiro de 2015 no local do atentado, a sede do semanário CHARLIE HEBDO, na França. Qual seria seu sentimento, opinião. Você seria o terrorista ou cartunista, explique sua escolha.

Cite o que aprendeu sobre a religião islâmica nas aulas de história?

6 Disponível em: https://www.pragmatismopolitico.com.br/2015/01/charges-mais-polemicas-da-charlie-hebdo.html. Acesso em: 2 set. 2016. 


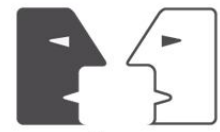

ANTÍTESES

\section{Anexo B}

Instrumental de Investigação das narrativas dos estudantes em avaliação sobre o atentado ao Semanário Charlie Hebdo

QUESTÕES DA AVALIAÇÃO DE HISTÓRIA . TRIMESTRE DE 2017.

SOBRE O ATENTADO AO SEMANÁRIO CHARLIE HEBD

No dia 07 de janeiro de 2015, ocorreu em Paris na França o atentado ao SEMANÁRIO CHARLIE HEBDO, observe as charges do semanário, e explique as seguintes sentenças:

Motivo de as charges serem ofensivas a Religião Islâmica:

Explique o que é Intolerância Religiosa em nossa sociedade hoje:

Tem ocorrido muitos atentados na Europa desde 2004, cite algum e fale quais razões poderiam ter gerado os mesmos.

Recebido em 06/11/2018

Aprovado em 09/01/2019 